\section{ON SOME POINTS IN THE MECHANISM OF FRACTURES OF THE CLAVICLE.}

By JOHN H. PACKARD, M.D. Surgeon to the Pennsylvania Hospital, and to St. Joseph's Hospital,
Philadelphia.

In the number of the Britisir Medical Journal for July 19th, there was a communication from Mr. Lush in regard to a case observed by him of fracture of the clavicle by the recoil of a gun; and another is reported by Mr. Prothero in the number of August 9th. In both instances, the fractures were of the simple variety, and united without difficulty.

The mere fact of these cases being placed upon record, would seem to indicate that they were thought by the reporters to be unusual. Yet accidents of this kind are, in reality, by no means rare. During the "reed-bird" season, they often occur among the sportsmen on the marshes near this city. The reed-bird, known elsewhere as the rice-bird or bob-o-link, is a small bird, flying in large flocks; and, in getting them, large loads of small shot are used. The gunners stand in boats, pushed by a man in the stern; they become careless, and are, indeed, often inexperienced, firing rapidly, and without fairly bringing the butt of the gun against the shoulder. Hence it not unfrequently happens that the recoil comes against the outer end of the clavicle, and in a somewhat downward direction if the birds be flying well over.

Duck-shooters, lying down in a boat or blind, and firing upward at birds flying high, are even more liable to this accident, the chances of which are increased by the use of very long and heavy guns.

Now, the mechanism of these fractures I believe to be, as I suggested as long ago as 1866, by leverage over the first rib. (New York Medical Journal, October, 1866.) It should be remembered that the sternal end of the clavicle is firmly fixed, and that the range of motion of the acromial end is but limited ; and between the inner portion of the clavicle and the first rib there is often a very close relation. In some persons, the upper part of the thorax comes much more nearly to a point than in others, the arch of the first rib being smaller, and the bone itself more delicate. Again (and these two conditions, I think, generally correspond), in some persons, the clavicle is straighter and stands out more directly from the sternum, than in others. When the first rib forms a wide and strong arch, and the collar-bone runs somewhat backward as well as closer to the rib, the two bones may be almost in contact, as far nearly as to the middle of the clavicle. Under such circumstances, it may easily be perceived how sudden violence, driving the outer end of the clavicle downward, or downward and backward, would act upon it as a lever, and tend to break it at its weakest point. The rib, being a strongly stayed arch, pressed upon at its convexity, would not give way ; while the clavicle would be taken at a disadvantage, being subjected to a force at its concavity, tending to increase its curvature. Very possibly, this leverage may have something to do with some fractures by indirect violence, as when a man falls forward on his outstretched hand, and the scapula is driven backward, carrying with it the acromial end of the clavicle. And I believe it affords the true explanation of those cases in which the clavicle gives way to muscular violence, as in striking a blow with a whip at a dog, or pulling down the brace of a carriage-top. In these and all the other recorded instances, the action was such as to forcibly and suddenly depress the outer end of the bone.

The other point of which I would speak is the mechanism of the displacement in fractures of the clavicle. With regard to this, most authors simply say that the weight of the shoulder causes it to drop; and in a recent paper by Mr. C. W. Cathcart, published in the British MEdical Jodrnal for August 30th, this view is discussed at some length. He argues that the weight of the shoulder is not normally supported by a strain on the shaft of the clavicle, but that, as pointed out independently by Cleland and Duchenne, the shoulder is really suspended in position by the action of the trapezius muscle. The traction, he thinks, is not direct, but to a certain extent indirect, the clavicle acting as a lever, with its fulcrum at the sternoclavicular joint. In a later paper (published on October 25th), he speaks of the bone as acting like the oblique beam of a crane "in supporting the weight of the arm"; and says that the "thrust" from within is lost when the bone is broken. Now it seems to me that in this last phrase he gives a more significant fact than he himself perceives.

I question whether the weight of the arm is in any material degree supported upon the clavicle; but this would be a matter requiring a good deal of space for its discussion; and I would merely suggest that when the clavicle-a purely "intermediate" bone-gives way, the muscles, which are the real agents of suspension, are as a general rule unimpaired. There must be some other reason for the downward, forward, and inward displacement so uniformly met with ; and such a reason, I think, may be found in the action of certain muscles.

As soon as the integrity of the clavicle is lost, the serratus magnus and pectoralis minor rack the scapula forward around the thorax, while the rhomboideus major tilts its lower angle upward. Hence the acromion is lowered and moved toward the median line anteriorly, pushing the outer fragment of the clavicle before it. Should the line of fracture be just within the insertion of the subclavius, this muscle would tend to act in the same way, drawing the outer fragment toward the sternum ; but this would, in most cases, be only a trifling accessory. The effect above described can be produced by the serratus magnus and pectoralis minor, and by them alone; nor is it opposed by any of the other muscles of the shoulder.

Very striking confirmation of the view now stated is afforded in the account given by Malgaigne of a patient of his who had an ununited fracture in each clavicle.

"Both clavicles had been broken at the middle; the two inner fragments were nearly horizontal, and very distinct beneath the skin ; the outer fragments had also a nearly horizontal direction, but were buried behind and below the others, to which they seemed to have no adhesions of any kind. The overlapping was considerable...... Posteriorly, the scapulæ were separated from the spinal column by three or four inches, and inclined forward and outward; and on the whole the thorax seemed much contracted at its upper part.

"He could draw the shoulders back a little, but not enough to overcome their apparent prominence anteriorly. On the other hand, he could draw them together forwards, so that they seemed like wings covering the chest, and leaving between them, in front of the sternum, only three inches' space. In this-movement, the scapulæ fitted to the sides of the trunk, and the back seemed rounded from one side to the other, almost like that of a skeleton deprived of its upper extremities" (Traité des Fractures, etc., tome i, p. 496).

At the time (1866) when I first published this view, I was not aware that it had been already advanced by Professor Gordon, of Belfast, in a communication to the Belfast Medical Society (sec Dublin Quarterly Journal of Medical Science, November 1859). Nor was he probably aware of my statement of it when he, in 1875, issued his Treatise on Fractures of the Lower End of the Radius, on Fractures of the Clavicle, etc. Certainly, we neither of us succeeded in gaining the consideration which, as it seems to me, the correctness of the theory deserved.

Now the practical bearing of the explanation above given is by no means unimportant. Restore the scapula to its position, and the outer fragment of the clavicle is also drawn into place. It is useless to push up the shoulder, and to put pads in the axilla, and to bring the elbow forward and inward. The scapula itself is the thing to be acted upon. For this purpose, the best apparatus yet devised seems to me to be that of Dr. Sayre, of New York, consisting of two wide strips .of adhesive plaster, so applied as to draw the upper part of the humerus, and with it the scapula, toward the median line of the back. A detailed description of the method may be found in many works on surgery. Rest on the back for the first week or ten days, if submitted to by the patient, would be a valuable accessory to its efficiency.

\section{EXPERIMENTAL RESEARCHES ON DIPHTHERIA.}

Read before the Lancashire and Cheshire Branch.

By CHARLES J. RENSHAW, M.D., Ashton-Upon-Mersey.

I MADE the following experiments on animals, with diphtheritic membrane.

On June 1st, 1874, I administered membrane of diphtheria to one cat ; on June 3rd, to two mice; on June 5th, to a rat; on July 2 nd, to two cats ; on August 7 th, to a cat ; on August 21st, to a cat ; on September 3rd, to three mice ; and on September 3rd, 7th, and 18th, to three hens. The result in all was negative. The membrane was of a yellowish white appearance. All the patients from whom the membrane was taken had enlargement of the lymphatic glands at the angle of the jaw, and three of the cases suffered afterwards from paralysis. Five cases had albuminuria, commencing on the second, third, fifth, and ninth days respectively. There was no doubt as to the membrane being that of diphtheria.

On June 6th, 1874, having seen that the stomach and bowels of a 